\title{
Increased sensitization rate to tree pollen of allergic children and altered pollen season in Seoul metropolitan area, Korea
}

\author{
Kyung Suk Lee ${ }^{1}$, Kyunghoon Kim² ${ }^{2}$ Young-Jin Choi ${ }^{3}$, Seung Yang ${ }^{3}$, Chang-Ryul Kim ${ }^{3}$, \\ Jin-Hwa Moon ${ }^{3}$, Kyu Rang Kim ${ }^{4}$, Yung-Seop Lee ${ }^{5}$, and Jae-Won $\mathrm{Oh}^{3}$ \\ ${ }^{1}$ Hanyang University \\ ${ }^{2}$ Catholic University of Korea College of Medicine \\ ${ }^{3}$ Hanyang University College of Medicine \\ ${ }^{4}$ National Institute of Meteorological Sciences \\ ${ }^{5}$ Dongguk University College of Natural Science
}

December 1, 2020

\begin{abstract}
Introduction: Children with allergy may increase a chance to sensitize the allergic pollens with several environmental changes. Purpose of this study was to investigate the correlation with alternation of pollination associated with meteorological changes and increased sensitization rate of pollen allergens of children in Seoul metropolitan area, Korea. Methods: There were recruited 8,295 children who visited the pediatric allergic clinics at Hanyang University Seoul and Guri Hospital for allergy symptoms from January 1st, 1998 to December 31st, 2019. The pollen was collected by Burkard 7 days-sampler in 2 hospitals during the study. Meteorological data was investigated from Korea Meteorological Administration. Results: Allergic sensitization of oak, hazel, and alder pollens had the highest rate of increase among major tree pollens, an increase of $0.28 \%$ annually. The sensitization rate to pollen was increased with younger age group yearly. The duration of pollen season was 98 days in 1998 , but 140 days in 2019. The duration of the pollen seasons and pollen sensitization rate to trees were positively correlated. The relationship between the sensitization rate to pollens and accumulated temperature were also correlated, positively. Conclusions: This study demonstrates the correlation between the weather changes and consequent changes of pollen seasons with increasing the sensitization rate to allergic pollens in children in Seoul metropolitan area. In addition, there was an increase in the sensitization rate in younger age group from year to year. Continuous changes in distribution of pollens raised from meteorological changes are expected from now on.
\end{abstract}

\section{Introduction}

Sensitization to pollen plays a crucial role in the development of allergic disorder, ${ }^{1}$ which has been reported to lead to more serious allergic symptoms and to increase the risk of asthma. ${ }^{2-3}$. An interaction between the exposure to pollen and being sensitized to pollen allergens was detected that the effect was less pronounced in individuals who were sensitized to only one type of pollen, compared with who are sensitized to all types of pollen. Furthermore, as different pollen types are released at different periods of the pollen season, atopic individual sensitized to more than one type of pollen are experiencing a longer period of exposure, which may lead to a stronger effect on airway hyperreactivity and reduced lung function. ${ }^{4}$

Pollen season is related to the flowering season, for pollen has to be previously produced and emitted by mature flowers. Weather variables, mainly air temperature, sunshine and rainfall, together with $\mathrm{CO}_{2}$ are among the main factors affecting phenology and pollen production by plant.

The weather may be the most crucial factor because it can alter the starting and ending of pollination and affect the change of pollen season directly although there are several environmental factors such as 
greenhouse gases, the other air pollutants. Weather conditions may subsequently influence the occurrence of allergic diseases such as asthma, allergic rhinitis. A growing number of people are contracting allergic diseases caused by pollen because of weather change in the world. ${ }^{5}$

The start and end of the pollen season itself, as defined by airborne pollen, may be influenced by factors affecting pollen dispersal, and may not coincide exactly with the maturation of the flowers. Longer pollen season and larger the amount of atmospheric pollen could enhance the human exposure to allergic pollens. These might relate with an increase in allergic sensitization. As the sensitization rate to pollen has increased in children recently, allergic plants which is rapidly proliferating, has emerged as a dangerous element to allergic children. It is now essential to survey pollens around the patient for the management of pollen allergy. ${ }^{6-8}$

A number of studies on the climate change effects on allergenic pollen distribution have focused on analyses of observed pollen counts and their regression relationships with local meteorological factors. Ongoing climate change, through rising the concentration of atmospheric $\mathrm{CO}_{2}$ and temperatures, contribute to extension of seasonal duration and increase in multiple pollen load. ${ }^{8}$ In an experimental study, warming and changes in $\mathrm{CO}_{2}$ were demonstrated an increase in pollen production. ${ }^{9,10}$ Elevated $\mathrm{CO}_{2}$ concentrations resulted in early pollen production from trees and greater seasonal pollen production. ${ }^{11,12}$ In addition, weather patterns influence the movement and dispersion of all aeroallergens in the atmosphere through the action of winds, rainfall and depending on the atmospheric stability.

This study investigated the reasons for recent rising pollen allergy and the sensitization rate to pollen has increased in children recently, and the relationships between the changes in start and end dates of pollination and weather changes for the past 22 years in Seoul metropolitan area. The results of the analysis are used in an attempt to predict trends in start dates in future. This study has important implications for the use of phenology as an indicator of weather changes and also for recent rising pollen allergy in children in Korea.

\section{Method and Materials}

\section{Pollen identification, counting and definition of pollen season}

Pollens were identified and counted from Hanyang University Seoul and Guri hospitals for over 22 years (1998 2019). Pollen sampling has been undertaken at the sites with Burkard Seven-days Sampler (Burkard Manufacturing Co Ltd., Hertfordshire, UK) on exposed roof tops during the study. Cumulative pollen concentrations and a preset percentage threshold level are used to define the start and end of the pollen season. The present study applied the $5 \%$ threshold method, which gave the smallest standard deviation in the start dates. ${ }^{13}$

\section{Selection of subject and sensitization rate to allergenic tree pollen}

Subjects for this study were selected by using the allergy skin prick test and the quantitative serum test for allergen-specific IgE level. Over 3 class levels of a pollen allergen-specific serum IgE or $>3+$ level of allergic skin prick test to pollen are an indication of sensitization to the allergenic pollen. ${ }^{14}$ Pollen for allergy test were birch, alder, oak, hazel, pine, willow. Sensitization rate to allergenic pollen was defined as a percentage of the number of the patients who sensitized allergenic pollen in the overall population taken allergy tests. Five age group were divided for the evaluation of change of age distribution $\left(3^{\sim} 5,6^{\sim} 9,10^{\sim} 12,13^{\sim} 15\right.$, and $16^{\sim} 18$ age of years).

\section{Meteorological data}

Daily records of the climatic variables such as mean temperature, rainfall, accumulated temperature and 7-days sunshine amount from the Korea Meteorological Administration (KMA) were used to represent the daily weather conditions near to the pollen monitoring site. The nearest weather stations to each pollen sampling site were selected to provide a number of meteorological data. The accumulated temperature defined the summed up temperature from $1^{\text {st }}$ January until the starting day of pollination, which is the most influential variables to pollination among meteorological variables and was selected for this study. 


\section{Statistical analysis}

We aimed to assess long-term pollen data to ascertain potential links to sensitization rate during the collection period. $\mathrm{R}$ version 4.0.2 (The $\mathrm{R}$ foundation, https://www.r-project.org) was used to ascertain statistical analysis. The changes of pollen sensitization were assessed by linear regression and time series analysis. A standardized regression coefficient by a method of least square for minimizing the sum of squared residuals is estimated, and which independent variable has a large influence on the dependent variable is found out. ${ }^{15}$

The correlation between the duration of the pollen season with starting date and pollen sensitization was assessed by correlation analysis. Long-term prediction of variation of pollen season was assessed by ARIMA11 analysis. Time series data are provided after seasonal adjustment. The ARIMA-11 analysis may also backcast previous year data from the starting point of the data, predict the year data from the ending point of the data, and solve the missing value problem by moving average of the expanded data. ${ }^{16}$

\section{Ethics statement}

This study was approved by the institutional review board of the Hanyang University Guri Hospital (IRB No. HYI-10-45). The requirement for informed consent from patients was waived, as the study was a retrospective analysis.

\section{Results}

\section{Study population}

In total 8,295 children (male: 4,032, female: 4,263; age: $3 \sim 18$ years old) visited two pediatric allergic clinics for allergy symptoms between 1998 and 2019. Table 1 shows the diagnosis of the subjects in this study and allergic rhinitis was most common in the subjects (Allergic rhinitis: 2,295, Atopic dermatitis: 2,259, asthma: 1,736, and the others: 2,005).

\section{The sensitization rates to allergic pollen}

Allergic sensitization rate for tree pollens has been increased from year to year. The first pollen observations tended to be moved forward and increased the duration of pollen seasons. The sensitization to tree pollens was gradually increased for the last 22 years (Table 2). Sensitization to oak, hazel, and alder pollens had the highest rate of increase $(0.28 \%$ annually), followed by that to birch, willow, and pine pollens $(0.25 \%, 0.25 \%$, and $0.23 \%$, respectively) (Table 2). Regarding age distribution changes for the last 22 years, sensitization rate to pollens was increased in $<10$ age of years (Age 3 5 years: 8.3\%, 6 $\sim$ years: $14.4 \%$, $10^{\sim} 12$ years: $24.0 \%, 13 \sim 15$ years: $25.4 \%$, and 16 18 years: 27.6 at 1998; Age $3^{\sim} 5$ years: $10.7 \%, 6 \sim 9$ years: $17.7 \%, 10^{\sim} 12$ years: $22.5 \%, 13^{\sim} 15$ years: $23.9 \%$, and $16^{\sim} 18$ years: 25.3 at 2019) (Fig. 1).

\section{Pollen seasons assessment}

The start and end dates of pollen season were March 5 and June 7, respectively and the pollination duration was 94 days in 1998. Meanwhile, the the start and end dates were February 15 and July 5, respectively and the pollen season duration was 140 days in 2019 (Fig. 2). Total concentration and peak concentration of pollens were increased gradually for the last 22 years (Fig. 3). These data implied the start and end date of tree pollination in the future at Seoul metropolitan area was predicted to widen the interval as the start day and the end date will be February $9^{\text {th }}$ and June $24^{\text {th }} 2027$, by using ARIMA-11 analysis. (Table 3 ). Accumulated temperature is critically correlated to pollination. Herein, the mean accumulated temperature at start day was $182.14 \pm 52.02^{\circ} \mathrm{C}$ during the pollination (Table 2). Both variables are critical correlated to pollination. Annual changes in the pollen season showed the start date became earlier and the end date later from 1998 to 2019 in Seoul metropolitan area.

4. Relationship of the sensitization rates to pollens with the pollen seasons duration and meteorological observation .

Regression model for each tree demonstrated that sensitization rate to oak, hazel, pine, birch, alder, and willow was increased $0.28 \%, 0.28 \%, 0.23 \%, 0.25 \%, 0.28 \%$, and $0.25 \%$ from year to year during 22 years 
respectively. The duration of the pollen seasons was positively correlated with the sensitization rate to oak, hazel, pine, birch, alder, and willow $(\mathrm{r}=0.79,0.81,0.85,0.79,0.80$, and 0.70 , respectively). The sensitization rate to pollens was positively correlated with the accumulated temperature also positively correlated (correlation coefficient: Oak 0.71; hazel 0.66; pine; 0.53, birch 0.69; alder 0.53; willow 0.64) (Table 2). The other meteorological data were not shown the significant relation to sensitization rate with pollen seasons duration.

\section{Discussion}

Studies of sensitization rate to pollen have been insufficient because of the lower allergenicity of pollen than that of house dust mites. Further, only a few studies have investigated sensitization in childhood. The present study is to investigate the change of sensitization rates to pollen in children with allergic diseases taken allergy test with altered pollen season for last 22 years. The present outcomes have important implications for the use of phenology as an indicator of meteorological changes. A shift in the timing of the common tree pollen season is important as known pollens also may aggravate the symptoms of respiratory allergic diseases. The outcome might be implied to increase the sensitization rate to tree pollen and pollen allergy from year to year for the past 22 years, and the age of sensitization rate to common tree pollens was also extended to younger children under 10 age of year.

Allergic rhinitis and allergic conjunctivitis have been presented over teen aged children ${ }^{9}$ but a number of pediatrician and allergists have reported a gradual increase in the prevalence of allergic diseases in children aged $<6$ years. ${ }^{17}$ The present study focused on the allergic children with age $3^{\sim} 18$ years old at Seoul metropolitan area for the last 22 years.

As pollen exposure rates differ depending on annual weather, sensitization rates were characterized according to these differences in the present study. There may be implied 3 primary means by which weather change could influence allergic sensitization to pollen.

First, warmer temperature due to climate change might increase seasonal intensity of the allergenic load and the concentration of pollen. ${ }^{18}$ Second, climate change could increase the level of allergenic pollens and allergic symptoms associated with exposure, including impacts on pollen amount, and pollen season. ${ }^{2,3}$ Finally, $\mathrm{CO}_{2}$ concentration and warmer temperature increase pollen concentration. And increased $\mathrm{CO}_{2}$ might alter the allergenicity, or allergen concentration of the pollen, and symptom severity. ${ }^{11,12}$

The pollen season was expanded and the concentration of pollens and sensitization rate to pollens were increased from year to year in the present study. Sensitization to allergens is an important step in the development of allergic diseases. A longer pollen season and increased pollen amount could increase the opportunity of human exposure to pollen as aeroallergens with consequences for increased allergic sensitization in childhood. ${ }^{17,19}$

There have been a few epidemiological and experimental studies on the relationship between allergic diseases and environmental and climate changes. ${ }^{20,21}$ An epidemiological study presented sensitization rate to tree pollens was significantly increased to $36.4 \%$ in the 2010 s from $19.0 \%$ in the $1990 \mathrm{~s}$ and $8.8 \%$ in the $1980 \mathrm{~s}$ in Korea. ${ }^{22}$ The nationwide prevalence of "diagnosis of allergic rhinitis, ever" was reported $15.5 \%, 20.4 \%$, and $28.5 \%$ in 1995, 2000, and 2006, respectively in the Korean version of the International Study of Asthma and Allergies in Childhood of Korean children. ${ }^{23,24}$

Younger children might increase sensitization rate to pollen compared to over 10 years old children with the altered pollen season in this study. A study for children also reported the age for sensitization to weed pollens gradually became younger (4 to 6 year of age, $3.5 \%$ in 1997 and $6.2 \%$ in 2009; 7 to 9 year of age, $4.2 \%$ in 1997 and $6.4 \%$ in 2009). ${ }^{17}$ Difference in exposure rates to allergens with increasing age result in difference in sensitization rates. Although the effects of environmental change on respiratory allergic diseases are not completely understood, these differences in sensitization rates may be implied different living environments such as the playing outdoor and going to school in young children, conversely adolescent stay the indoor due to hard study or playing videogames with recent trend in Korea. It may be useful to manage allergic diseases 
by continuous investigation and systematical observation of the regional differences and chronological changes of living environments.

Oak, hazel, and alder were shown the sharpest slope to raise sensitization rate among tree species and more related between sensitization rate and pollen season except pine which is no to mild allergenic, during this study. Oak is expected to dominate over other species during the vegetation transition, ${ }^{25}$ so that its distribution will be broader. By developing phenological models based on weather conditions, one can assess future oak species distribution and length of the pollen season. Hazel pollen is important, resulting in asthma and allergic rhinitis in hazel pollen-allergic individuals, in particular in early spring. ${ }^{26,27}$ Alder pollen also is a significant cause of asthma, allergic rhinitis, and allergic conjunctivitis, in particular in Spring and in conjunction with birch and hazel pollen. ${ }^{28,29}$ In patients with poly-sensitization to alder, hazel, and oak pollen who were cross-reactive, initial symptoms occurred as early as February, with abrupt exacerbation in March to May.

The accumulated temperature was the most influential variables to pollination among meteorological variables in this study. Sensitization rate to oak and birch had the highest correlation to accumulated temperature among the subjected trees. Birch has reproductive rhythms of high and low years for the abundance of pollen and subsequent seed and pollination is dependent on the temperature. ${ }^{30}$

In conclusion, this study demonstrated the positive correlation between the consequent changes of pollen seasons and the raising sensitization rate to major tree pollens in childhood in Seoul metropolitan area for the past 22 years and continuous increase in concentration of pollens due to weather changes were expected. The sensitization rate increased in younger children from year to year. This might imply that climate change impact to alter the pollen season and consequently to increase the sensitization rate to allergic tree pollens in children.

\section{AUTHOR CONTRIBUTIONS}

Kyung Suk Lee: Conceptualization (equal); Data curation (equal); Formal analysis (equal); Writingoriginal draft (equal); Writing-review \& editing (equal). Kyunghoon Kim: Conceptualization (equal); Data curation (equal); Formal analysis (equal); Writing-original draft (equal); Writing-review \& editing (equal). Young-Jin Choi: Data curation (equal); Formal analysis (supporting); Writing-review \& editing (supporting). Seung Yang: Formal analysis (equal); Supervision (supporting); Writing-review \& editing (supporting). Chang-Ryul Kim: Conceptualization (supporting); Formal analysis (equal); Supervision (equal). Jin-Hwa Moon: Formal analysis (equal); Supervision (equal); Writing-review \& editing (supporting). Kyu Rang Kim: Data curation (equal); Formal analysis (equal); Writing-review \& editing (equal). Yung-Seop Lee: Data curation (equal); Methodology (equal); Formal analysis (equal); Writing-review \& editing (equal). Jae-Won Oh: Conceptualization (equal); Data curation (equal); Formal analysis (equal); Funding acquisition (lead); Methodology (lead); Supervision (lead); Writing-original draft (equal); Writing-review \& editing (equal).

\section{References}

1. Bousquet PJ, Burbach G, Heinzerling LM, et al. GA2LEN skin test study III: minimum battery of test inhalent allergens needed in epidemiological studies in patients. Allergy. 2009;64:1656-62.

2. Schatz M, Rosenwasser L. The allergic asthma phenotype. J Allergy Clin Immunol Pract. 2014;2:645-648; quiz 649 .

3. Zoratti E, Havstad S, Wegienka G, et al. Differentiating asthma phenotypes in young adults through polyclonal cytokine profiles. Ann Allergy Asthma Immunol. 2014;113:25-30.

4. Schoos AM, Jelding-Dannemand E, Stokholm J, Bonnelykke K, Bisgaard H, Chawes BL. Single and multiple time-point allergic sensitization during childhood and risk of asthma by age 13. Pediatr Allergy Immunol. 2019;30:716-723. 
5 D'Amato G, Holgate ST, Pawankar R, Ledford DK, Cecchi L, Al-Ahmad M, Al-Enezi F, Al-Muhsen S, Ansotegui I, Baena-Cagnani CE, Baker DJ, Bayram H, Bergmann KC, Boulet LP, Buters JT, D'Amato M, Dorsano S, Douwes J, Finlay SE, Garrasi D, Gomez M, Haahtela T, Halwani R, Hassani Y, Mahboub B, Marks G, Michelozzi P, Montagni M, Nunes C, Oh JW, et al. Meteorological conditions, climate change, new emerging factors, and asthma and related allergic disorders. A statement of the World Allergy Organization. World Allergy Organ J. 2015;14:1-25.

6 Lee SW, Yon DK, James CC, Lee S, Koh HY, Sheen YH, Oh JW, Han MY, Sugihara G. Short-term effects of multiple outdoor environmental factors on risk of asthma exacerbations: Age-stratified time-series analysis. J Allergy Clin Immunol. 2019;144:1542-50.

7 Park HJ, Lee JH, Park KH, Kim KR, Han MJ, Choe H, Oh JW, Hong CS. A Six-Year Study on the Changes in Airborne Pollen Counts and Skin Positivity Rates in Korea: 2008-2013. Yonsei Med J. 2016;57:714-20.

8. Ziska LH, Makra L, Harry SK, Bruffaerts N, Hendrickx M, Coates F, et al. Temperature-related changes in airborne allergenic pollen abundance and seasonality across the northern hemisphere: a retrospective data analysis. Lancet Planet Health. 2019;3:e124-e31.

9 Wan S, Yuan T, Bowdish S, Wallace L, Russell SD, Luo Y. Response of an allergenic species, Ambrosia psilostachya (Asteraceae), to experimental warming and clipping: implications for public health. Am J Bot. 2002;89:1843-6.

10 Wayne P, Foster S, Connolly J, Bazzaz F, Epstein P. Production of allergenic pollen by ragweed (Ambrosia artemisiifolia L.) is increased in CO2-enriched atmospheres. Ann Allergy asthma Immunol 2002;88:279-82.

11 Kim KR, Oh JW, Woo SY, Seo YA, Choi YJ, Kim HS, Lee WY, Kim BJ. Does the increase in ambient CO2 concentration elevate allergy risks posed by oak pollen? Int J Biometeorol 2018;62:1587-94.

12 Choi YJ, Oh HR, Oh JW, Kim KR, Kim MJ, Kim BJ, Baek WG. Chamber and field studies demonstrate differential Amb a 1 contents in common ragweed depending on CO2 Levels. Allergy Asthma Immunol Res $2018 ; 10: 278-82$.

13 Bastl K, Kmenta M, Berger UE. Defining Pollen Seasons: Background and Recommendations. Curr Allergy Asthma Rep 2018;18:73. doi: 10.1007/s11882-018-0829-z.

14 Wolthers OD, Staberg M. The usefulness of the multiple allergen simultaneous test-chemiluminescent as compared to the Phadia Immunocap IgE test panel system in children and adolescents. Recent Pat Inflamm Allergy Drug Discov 2013;7:96-9.

15 Chatterjee, Samprit, Ali S. Hadi. Regression analysis by example. New Jersey: John Wiley \& Sons; 2006. $1-82$.

16 William W.S. Wei. Time series analysis. Bloomington: Pearson; 2006. 160-9.

17 Kim JH, Oh JW, Lee HB, et al. Changes in sensitization rate to weed allergens in children with increased weeds pollen counts in Seoul metropolitan area. J Korean Med Sci 2012;27:350-5.

18 Kuparinen A, Katul G, Nathan R, Schurr FM. Increases in air temperature can promote wind-driven dispersal and spread of plants. Proc Biol Sci. 2009;276:3081-87.

19 Beggs PJ. Climate change and allergy in Australia: an innovative, high-income country, at potential risk. Public Health Res Pract 2018 Dec 6;28(4):2841828. doi: 10.17061/phrp2841828.

20 D'Amato G, Cecchi L. Effects of climate change on environmental factors in respiratory allergic diseases. Clin Exp Allergy 2008; 38: 1264-74.

21 Ayres JG, Forsberg B, Annesi-Maesano I, Dey R, Ebi KL, Helms PJ, Medina-Ramon M, Windt M, Forastiere F; Environment and Health Committee of the European Respiratory Society. Climate change and respiratory disease: European Respiratory Society position statement. Eur Respir J 2009; 34: 295-302. 
22 Park HJ, Lim HS, Park KH, Lee JH, Park JW, Hong CS. Changes in allergen sensitization over the last 30 years in Korea respiratory allergic patients: a single-center. Allergy Asthma Immunol Res 2014;6:434-43.

23 Hong S-J, Ahn K-M, Lee S-Y, Kim K-E. The prevalences of asthma and allergic diseases in Korean children. Korean J Pediatr 2008; 51: 343-50.

24 Jee HM, Kim KW, Kim CS, Sohn MH, Shin DC, Kim KE. Prevalence of asthma, rhinitis and eczema in Korean children using the International Study Of Asthma and Allergies In Childhood (ISAAC) questionnaires. Pediatr Allergy Respir Dis 2009;19: 165-72.

25 Choung Y, Lee BC, Cho JH, Lee KS, Jang IS, Kim SH, Hong SK, Jung HC, Choung H-L. Forest responses to the large-scale east coast fires in Korea. Ecol Res 2004;19:43-54.

26 Ebner C, Ferreira F, Hoffmann K, Hirschwehr R, Schenk S, Szepfalusi Z, Breiteneder H, Parronchi P, Romagnani S, Scheiner O, et al. T cell clones specific for Bet v I, the major birch pollen allergen, crossreact with the major allergens of hazel, Cor a I, and alder, Aln g I. Mol Immunol 1993;30:1323-9.

27 Eriksson NE, Wihl JA, Arrendal H, Strandhede SO. Tree pollen allergy. III. Cross reactions based on results from skin prick tests and the RAST in hay fever patients. A multi-centre study. Allergy1987;42:20514.

28 Piotrowska K. Comparison of Alnus, Corylus and Betula pollen counts in Lublin (Poland) and Skien (Norway). Ann Agric Environ Med. 2004;11:205-8.

29. Troise C, Voltolini S, Delbono G, Negrini AC. Allergy to pollens from Betulaceae and Corylaceae in a Mediterranean area (Genoa, Italy) - a ten-year retrospective study. J Investig Allergol Clin Immunol 1992;2:313-7.

30 Furlow, John J. Betula. In Flora of North America Editorial Committee (ed.). Flora of North America, North of Mexico (FNA). 3. New York and Oxford - via eFloras.org, Missouri Botanical Garden, St. Louis, MO \& Harvard University Herbaria, Cambridge, MA.1997.

\section{Tables}

Table 1. Diagnosis of the subjects with allergy sensitization to tree pollen

\begin{tabular}{llllll}
\hline Year & Total & Asthma & Allergic rhinitis & Atopic dermatitis & Others \\
1998 & 312 & 71 & 75 & 69 & 97 \\
1999 & 331 & 74 & 101 & 77 & 79 \\
2000 & 241 & 44 & 63 & 55 & 79 \\
2001 & 305 & 59 & 88 & 88 & 70 \\
2002 & 336 & 73 & 89 & 88 & 86 \\
2003 & 396 & 81 & 115 & 98 & 102 \\
2004 & 453 & 94 & 103 & 133 & 123 \\
2005 & 423 & 88 & 120 & 115 & 100 \\
2006 & 396 & 78 & 118 & 114 & 86 \\
2007 & 377 & 93 & 100 & 124 & 60 \\
2008 & 415 & 89 & 96 & 135 & 95 \\
2009 & 401 & 76 & 115 & 123 & 87 \\
2010 & 452 & 99 & 113 & 119 & 121 \\
2011 & 422 & 80 & 111 & 120 & 111 \\
2012 & 395 & 72 & 102 & 121 & 100 \\
2013 & 404 & 79 & 108 & 115 & 102 \\
2014 & 407 & 86 & 117 & 122 & 82 \\
2015 & 392 & 81 & 93 & 113 & 97 \\
2016 & 375 & 95 & 85 & 98 &
\end{tabular}




\begin{tabular}{llllll}
2017 & 390 & 72 & 141 & 90 & 87 \\
2018 & 357 & 83 & 136 & 76 & 62 \\
2019 & 315 & 69 & 106 & 66 & 74 \\
total & 8,295 & 1,736 & 2,295 & 2,259 & 2,005 \\
\hline
\end{tabular}

Table 2. Mean accumulated temperatures and sensitization rate to major tree pollen during the study

\begin{tabular}{|c|c|c|c|c|c|c|c|}
\hline Year & $\begin{array}{l}\text { Accumulated } \\
\text { tempera- } \\
\text { ture } \\
\left({ }^{\circ} \mathrm{C}\right)\end{array}$ & $\begin{array}{l}\text { Sensitization } \\
\text { rate to } \\
\text { pollen }(\%)\end{array}$ & $\begin{array}{l}\text { Sensitization } \\
\text { rate to } \\
\text { pollen }(\%)\end{array}$ & $\begin{array}{l}\text { Sensitization } \\
\text { rate to } \\
\text { pollen }(\%)\end{array}$ & $\begin{array}{l}\text { Sensitization } \\
\text { rate to } \\
\text { pollen }(\%)\end{array}$ & $\begin{array}{l}\text { Sensitization } \\
\text { rate to } \\
\text { pollen }(\%)\end{array}$ & $\begin{array}{l}\text { Sensitization } \\
\text { rate to } \\
\text { pollen }(\%)\end{array}$ \\
\hline & & Oak & Hazel & Pine & Birch & Alder & Willow \\
\hline 1998 & 206.35 & 4.7 & 4.0 & 3.2 & 4.2 & 2.6 & 3.8 \\
\hline 1999 & 153.80 & 5.1 & 3.5 & 3.3 & 4.5 & 4.3 & 4.7 \\
\hline 2000 & 163.60 & 4.9 & 3.1 & 5.1 & 4.8 & 3.3 & 3.7 \\
\hline 2001 & 140.55 & 5.3 & 3.8 & 4.3 & 5.1 & 3.8 & 4.3 \\
\hline 2002 & 158.85 & 4.8 & 4.3 & 5.4 & 4.8 & 4.6 & 4.7 \\
\hline 2003 & 133.85 & 5.0 & 4.1 & 5.8 & 5.5 & 3.8 & 3.6 \\
\hline 2004 & 170.15 & 4.5 & 3.8 & 4.8 & 5.3 & 5.7 & 3.2 \\
\hline 2005 & 144.20 & 5.4 & 3.2 & 5.5 & 5.8 & 6.2 & 3.5 \\
\hline 2006 & 218.50 & 5.2 & 4.7 & 6.3 & 5.4 & 5.9 & 3.8 \\
\hline 2007 & 130.45 & 5.7 & 4.4 & 4.8 & 4.6 & 5.6 & 4.4 \\
\hline 2008 & 102.35 & 5.2 & 5.2 & 5.7 & 5.3 & 6.4 & 4.2 \\
\hline 2009 & 170.75 & 5.8 & 4.8 & 6.0 & 5.8 & 6.5 & 3.4 \\
\hline 2010 & 105.55 & 5.5 & 5.1 & 6.2 & 5.7 & 5.2 & 4.3 \\
\hline 2011 & 163.35 & 5.6 & 6.5 & 6.2 & 6.5 & 6.2 & 6.5 \\
\hline 2012 & 138.35 & 7.6 & 7.3 & 7.7 & 7.3 & 8.7 & 7.3 \\
\hline 2013 & 189.80 & 8.5 & 7.3 & 8.3 & 6.3 & 7.5 & 6.4 \\
\hline 2014 & 264.30 & 9.3 & 9.5 & 7.3 & 8.3 & 8.4 & 7.2 \\
\hline 2015 & 257.70 & 9.6 & 8.7 & 8.2 & 9.4 & 9.7 & 8.5 \\
\hline 2016 & 245.20 & 9.9 & 8.5 & 8.5 & 9.7 & 9.5 & 8.5 \\
\hline 2017 & 252.90 & 9.2 & 8.3 & 7.5 & 9.9 & 8.5 & 7.3 \\
\hline 2018 & 244.85 & 9.5 & 7.6 & 8.1 & 8.4 & 7.4 & 8.4 \\
\hline 2019 & 251.85 & 9.8 & 8.1 & 8.7 & 8.7 & 8.1 & 8.3 \\
\hline $\begin{array}{l}\text { Mean } \pm \\
\text { SD }\end{array}$ & $182.14 \pm 52.02$ & $6.64 \pm 2.03$ & $5.72 \pm 2.06$ & $6.22 \pm 1.63$ & $6.42 \pm 1.82$ & $6.27 \pm 2.03$ & $5.45 \pm 1.93$ \\
\hline $\begin{array}{l}\text { Correlation } \\
\text { coefficient } \\
(\mathrm{r}, \\
\mathrm{p}<0.05)^{*}\end{array}$ & $\begin{array}{l}\text { Correlation } \\
\text { coefficient } \\
(\mathrm{r}, \\
\mathrm{p}<0.05)^{*}\end{array}$ & 0.71 & 0.66 & 0.53 & 0.69 & 0.53 & 0.64 \\
\hline
\end{tabular}

Table 3. The prediction of starting and ending date of tree pollination in future at Seoul metropolitan area by using ARIMA-11 analysis.

\begin{tabular}{lll}
\hline Year & Starting date (Month/Day) & Ending date (Month/Day) \\
\hline 2020 & $2 / 16$ & $6 / 21$ \\
2021 & $2 / 15$ & $6 / 22$ \\
2022 & $2 / 14$ & $6 / 22$ \\
2023 & $2 / 13$ & $6 / 22$
\end{tabular}




\begin{tabular}{lll}
\hline Year & Starting date (Month/Day) & Ending date (Month/Day) \\
\hline 2024 & $2 / 12$ & $6 / 22$ \\
2025 & $2 / 11$ & $6 / 23$ \\
2026 & $2 / 10$ & $6 / 23$ \\
2027 & $2 / 09$ & $6 / 24$ \\
\hline
\end{tabular}

\section{Figure legends}

Fig 1. Age distribution of sensitization rate to major pollen in Seoul metropolitan area at study period. the pollen sensitization rate increased among $<10$ age of years children $\left(3^{\sim} 5\right.$ years: $8.3 \%, 6^{\sim} 9$ years: $14.4 \%$, $10^{\sim} 12$ years: $24.0 \%, 13^{\sim} 15$ years: $25.4 \%$, and $16^{\sim} 18$ years: $27.6 \%$ in $1998 ; 3^{\sim} 5$ years: $10.7 \%, 6 \sim 9$ years: $17.7 \%, 10 \sim 12$ years: $22.5 \%, 13 \sim 15$ years: $23.9 \%$, and $16 \sim 18$ years: $25.3 \%$ in 2019 ).

Fig 2. The start and end dates of pollen season of major allergenic tree pollens in Seoul metropolitan area during the past 22 years. The start and end dates of pollen season were March 5 and June 7 respectively and the pollination duration was 94 days in 1998, with the start and end dates as February 15 and July 5, respectively. Meanwhile, the pollen season duration was 140 days in 2019.

Fig 3. The trend of total concentration of pollens (A) and peak tree pollen concentration (B) in Seoul metropolitan area during the study. Total concentration and peak concentration of pollens were increased gradually for the last 22 years.

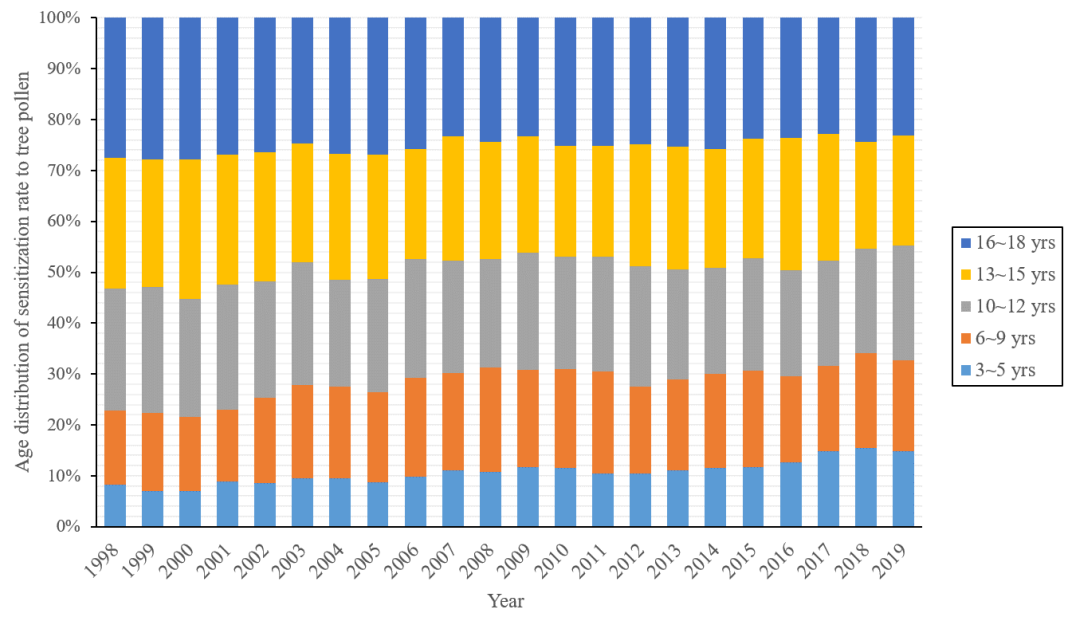




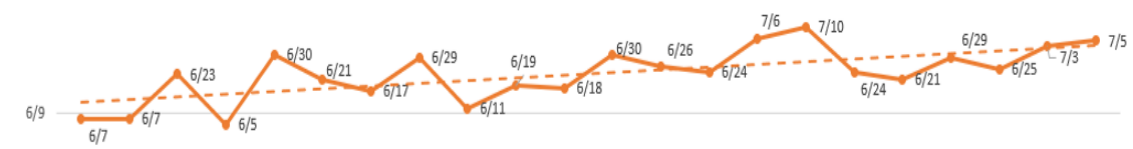

!

$3 / 31$

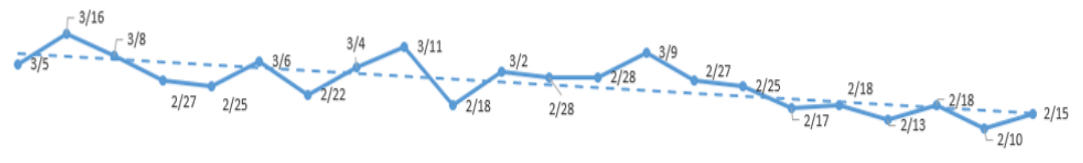

$1 / 20$

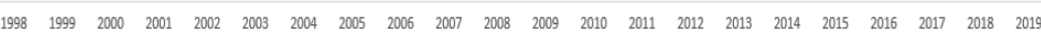

Year

Fig 3.
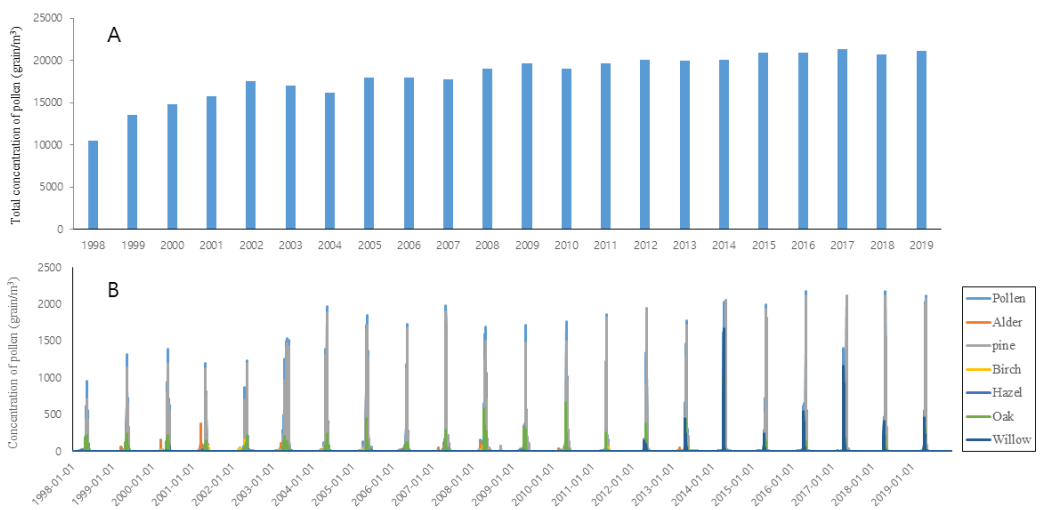